\title{
Analysis of environmental impact of activated carbon production from wood waste
}

\author{
Mi Hyung Kim', In Tae Jeong ${ }^{2}$, Sang Bum Park ${ }^{3}$, Jung Wk Kim ${ }^{\dagger}$ \\ ${ }^{1}$ BKT United, 1225 N Patt St. Anaheim, CA 92801, USA \\ ${ }^{2}$ R\&D Office, Korea Environmental Industry and Technology Institute, Seoul 03367, Republic of Korea \\ ${ }^{3}$ National Institute of Forest Science, Seoul 02455, Republic of Korea \\ ${ }^{4}$ Department of Environmental Planning, Graduate School of Environmental Studies, Seoul National University, Seoul 08826, Republic of Korea
}

\begin{abstract}
Activated carbon is carbon produced from carbonaceous source materials, such as coconut shells, coals, and woods. In this study, an activated carbon production system was analyzed by carbonization and activation in terms of environmental impact and human health. The feedstock of wood wastes for the system reduced fossil fuel consumption and disposal costs. Life cycle assessment methodology was used to analyze the environmental impacts of the system, and the functional unit was one tonne of wood wastes. The boundary expansion method was applied to analyze the wood waste recycling process for activated carbon production. An environmental credit was quantified by avoided impact analysis. Specifically, greenhouse gases discharged from $1 \mathrm{~kg}$ of activated carbon production system by feeding wood wastes were evaluated. We found that this system reduced global warming potential of approximately $9.69 \mathrm{E}+00 \mathrm{~kg} \mathrm{CO}_{2}$-eq. compared to the process using coals. The environmental benefits for activated carbon production from wood wastes were analyzed in contrast to other disposal methods. The results showed that the activated carbon system using one tonne of wood wastes has an environmental benefit of $163 \mathrm{~kg}$ $\mathrm{CO}_{2}$-eq. for reducing global warming potential in comparison with the same amount of wood wastes disposal by landfilling.
\end{abstract}

Keywords: Activated carbon, Environmental impact, Life cycle assessment, Recycling, Wood waste

\section{Introduction}

Pyrolysis is the thermal decomposition of organic materials in the absence of oxygen, and it is an initial stage of both combustion and gasification processes [1]. Activated Carbon (AC) is mainly prepared with the pyrolysis of carbonaceous raw materials at temperature lower than $1,000^{\circ} \mathrm{C}$. The most widely used AC adsorbents have a specific surface area of 800 to $1,500 \mathrm{~m}^{2} / \mathrm{g}$ and a pore volume of 0.20 to $0.60 \mathrm{~cm}^{3} / \mathrm{g}$ [2]. The utilization of $\mathrm{AC}$ is a common method in environmental sectors for removing pollutants from air or water streams in municipal and industrial processes, such as wastewater treatment plants, groundwater remediation, and air purification or oil removal by adsorption [3, 4]. Generally, AC is produced from a wide variety of carbon rich raw materials, including coal, peat, nut shell, coconut husk, wood, and municipal solid waste. Yahya et al. [5] reviewed that AC production derived from agricultural waste materials achieved large surface area, high micro- porosity and selectivity, and was relatively inexpensive, locally available. The carbon contents of these agricultural waste materials are lower than those of anthracite, coal or peat. Therefore the yields of AC from these precursors are expected to be lower [5]. However, lower cost required for AC production gives significant impact despite of its lower yield [6, 7].

The environmental impact associated with a specific AC varies because AC can be produced from various carbonaceous materials by physical or chemical activation, or by a combination of the two processes [8-10]. The production process of AC is classified in four sub-processes as follows: pre-treatment, carbonization, activation, and post-treatment. The pre-treatment process is a dehydration step for increasing production efficiency. The most important processes are the carbonization and activation processes. The carbonization process is conducted for the conversion of an organic substance into carbon by removing hydrocarbon and volatile compounds. Charcoal is produced from the process by low
This is an Open Access article distributed under the terms of the Creative Commons Attribution Non-Commercial License (http://creativecommons.org/licenses/by-nc/3.0/) which permits unrestricted non-commercial use, distribution, and reproduction in any medium, provided the original work is properly cited.
Received March 19, 2018 Accepted June 23, 2018

${ }^{\dagger}$ Corresponding author

Email: kimjw@snu.ac.kr

Tel: +82-2-547-5138

Copyright (C) 2019 Korean Society of Environmental Engineers 
temperature pyrolysis process in the range between 400 and $850^{\circ} \mathrm{C}$ with extremely limited air [11]. Feedstocks break down spontaneously in the carbonization process and continue until only the carbonized residue of charcoal remains. The yield of the carbonization process is around $20-30 \%$ of raw material [12]. The next step for AC production is the activation process for producing a microporous structure. This process is conducted at higher temperature ranging from 600 to $900^{\circ} \mathrm{C}$ than the carbonization process [11]. The activation process creates carbon, which provides a large surface area for adsorption. The yield of the activation process is approximately $15-25 \%$ of charcoal [12]. The activation process includes steam activation and chemical activation. For the steam activation, oxidizing gases, mainly steam, are used. For the chemical activation, alkali, such as potassium hydroxide, and sodium hydroxide, has been used as an activating agent [5, 13]. Another study reported that phosphoric acid and sulfuric acid are also used as a dehydrating agent in the process [8].

Life Cycle Assessment (LCA) is an effective environmental tool dealing with the complex interaction between the environment and a product or activity by quantifying consuming resources and effluent through whole life span of the products or systems, including acquisition of resources, manufacturing, use, treatment, recycling, and final disposal (from cradle to grave). Though LCA aims to be science-based, it involves a number of technical assumptions and value choices. One fundamental question is the selection of impact category weights in order to aggregate the total impact from various impact categories into a single score [14]. There are three commonly used groups of weighting methods [15] as follows: the panel method, the monetary method, and the distance-to-target method. In the distance-to-target approach, weights are derived from the extent to which actual environmental performance deviates from goals or standards. [14] As described by Powell et al. [16], the method ranks impacts as being more important, and the further away society is from achieving the desired standard for the pollutant. Despite of its limitations, the environmental impacts obtained from LCA are described as potential impacts because they are not specified in time and space [17-19].

LCA analysis has been commonly used to analyze the environmental impact for solid wastes including wood wastes disposal and/or recycling [20-25]. There are only few studies on LCA of the AC production process. Alhashimi and Aktas [26] analyzed environmental impact for biochar comparing with AC by LCA methodology. The study reported that average Greenhouse Gases (GHGs) emissions were calculated to be $-0.9 \mathrm{~kg} \mathrm{CO}$-eq. for one $\mathrm{kg}$ of biochar, and $6.6 \mathrm{~kg} \mathrm{CO}$-eq. for one $\mathrm{kg}$ of $\mathrm{AC}$, respectively. The environmental impact was calculated through a meta-analysis. Using LCA methodology, Bayer et al. [27] analyzed Granular Activated Carbon (GAC) refill systems from economic and ecological aspects. The emissions from GAC production from hard coal, transport, and recycling were equally derived through an LCA. Using LCA, Hjaila et al. [8] analyzed the environmental impact of AC production from olive waste cake. The AC was prepared via chemical activation using phosphoric acid as a dehydrating agent based on a laboratory scale [8]. The results showed that the environmental impacts were dominated by impregnation, followed by pyrolysis of the impregnated precursor, and finally by drying the washed AC.
The aim of this study was to review the production of AC from wood wastes and analyze their impacts on the natural environment and human health. Data were collected from the direct reviews at selected manufacturing companies, wood chips, wood charcoals, and AC production, and then, used for this study. Life Cycle Inventory (LCI) was constructed for each production step of chipping, drying, carbonization, and activation processes. Contaminants emitted from the production processes were analyzed using LCA methodology. Using the environmental credit analysis, we concentrated on analyzing Global Warming Potential (GWP) to comparative AC manufacturing process by feeding waste woods with coals and coconut shells which are mostly used. Tax issue on carbon emission regulations associated with climate change is an important international concern [28, 29]. Therefore, the characteristic GWP was finally selected as an environmental indicator to evaluate the impacts of global warming. Each GHGs value is quantified as carbon dioxide equivalents, according to Intergovernmental Panel on Climate Change (IPCC) indicators [30]. The GHGs include carbon dioxide $\left(\mathrm{CO}_{2}\right)$, methane $\left(\mathrm{CH}_{4}\right)$, nitrous oxide $\left(\mathrm{N}_{2} \mathrm{O}\right)$, chlorofluorocarbons (CFCs), hydrofluorocarbons (HFCs), perfluorocarbons (PFCs), and sulfur hexafluoride $\left(\mathrm{SF}_{6}\right)$. This study is expected to suggest the AC production from wood wastes as an alternative for waste management from the perspective of global warming.

\section{Methodology}

The LCA methodology used in this study follows the ISO 14040 and 14044 guidelines [31, 32]. The decision rules for the inclusion of input and output materials into the system boundary were cumulative weight, energy, and relevance to the environmental aspects, all suggested by ISO/TR 14049 [33, 34]. The environmental impacts of each stage were analyzed using LCA methodology and an indicator model. The LCI tool, TOTAL 5.0.1 developed by the Korean Environmental Industry \& Technology Institute (Seoul, South Korea), was used. The Korean eco-indicator model, which was chosen for this study, was applied by Lee [35] through the distance-to-target methodology. Distance-to-target methods are based on the assumption that all targets are equally important [36, 37].

\subsection{Goal and Scope of the Study}

The goal of the study was to evaluate the system for producing AC using an LCA methodology. LCA addresses potential of environmental impacts, such as the use of resources and the environmental consequences of releases throughout a product's life cycle from raw material acquisition through production, use, end-of-life treatment, recycling and final disposal, from cradle to grave [31]. This study was performed in four phases: goal and scope definition, inventory analysis, impact assessment, and interpretation supported by the international standard [32, 38]. All input and output data of the systems were constructed and evaluated to analyze the environmental impacts of the systems.

An expanded system boundary was applied for the comparison of different by-products of each scenario [39, 40]. The most appropriate method for the quantification of environmental credit (or benefit) 
Expanded system boundaries

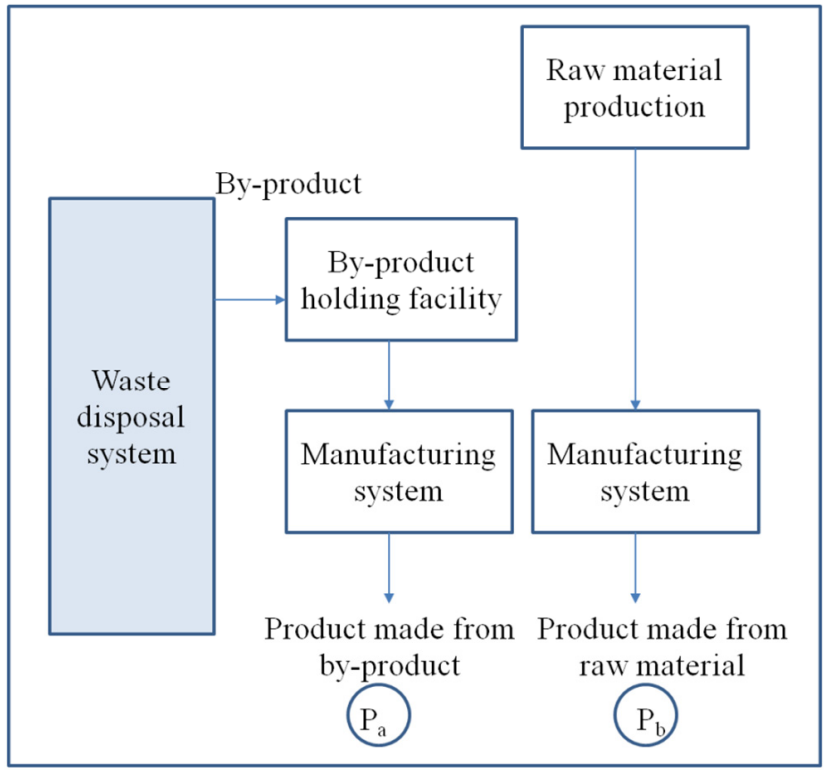

Environmental credit $=\mathrm{P}_{\mathrm{a}}-\mathrm{P}_{\mathrm{b}}$

Fig. 1. System boundary of by-product recycling for the quantification of environmental credit (Environmental credit $=\mathrm{P}_{\mathrm{a}}-\mathrm{P}_{\mathrm{b}}$ ).

that resulted from the recycling of by-products is the system expansion method as shown in Fig. 1. By-products generated from the product manufacturing process can be used as raw materials for other product systems, resulting in reduction of the use of virgin raw materials in the other product systems. It has been generally accepted that the use of recycled materials is environmentally preferable to that of virgin raw materials. This is because the environmental loads associated with the processing of recycled materials are less than those associated with the extraction and processing of virgin raw materials [41, 42]. The system boundary of this study is from the acquisition of resources from nature to the exit gate of the factory that produces product (raw material). Therefore, the product use stage and the end of life stages were excluded from the system boundary.

\subsection{Data Sources and Process Description}

Data were collected from the direct reviews at selected manufacturing companies, and used for this study. The geographical boundary of the study was Gyeonggi province, located in Western of South Korea. Data quality was reviewed by quantitative and qualitative aspects [43]. The time span covered in this study was the year 2015. The upstream and downstream databases related to the technosphere were collected by the Ministry of Environment and the Ministry of Trade, Industry and Energy. When measured data was missing, literature data and ecoinvent data were used. The technology coverage for AC production process from wood waste is shown in Fig. 2. The technology process design and operational conditions were optimized in the industrial scale. Raw material of wood waste was pretreated by chipping and drying steps. Pretreated wood waste put into a rotary kiln for carbonization. The carbonized charcoal was supplied to a rotary kiln for steam activation.

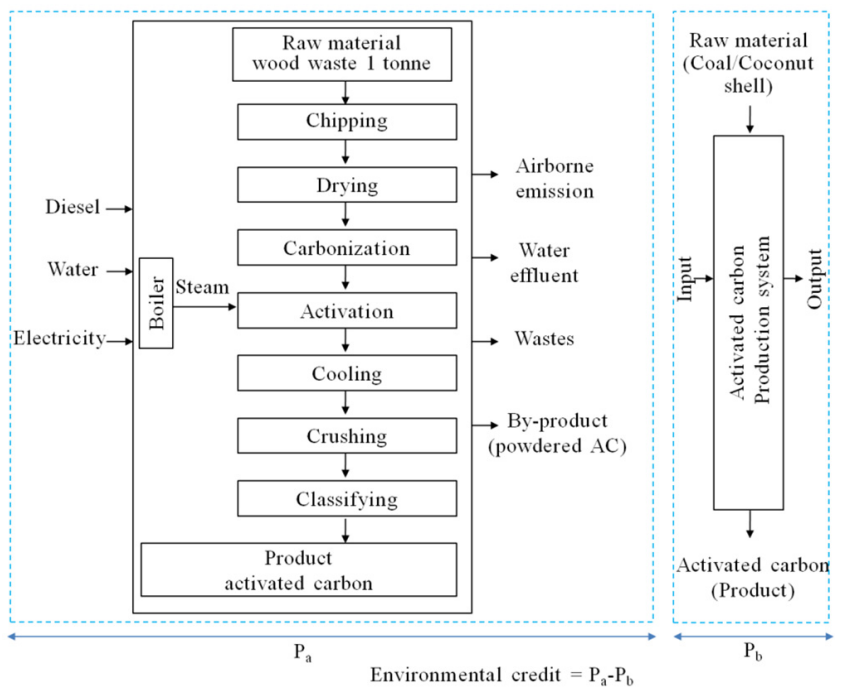

Fig. 2. The flow chart of AC production process from wood waste and expanded system boundary (Environmental credit $=\mathrm{P}_{\mathrm{a}}-\mathrm{P}_{\mathrm{b}}$ ).

The next steps for the final product were cooling, crushing, and classifying steps. Energy and materials were inserted to the system, and then, waste and by-product were produced from the system. The environmental credit was analyzed as the methodology for an expanded system boundary as presented in the process shown in Fig. 2.

\subsubsection{Pre-treatment process}

Wood waste was pretreated by chipping and drying processes to achieve the appropriate condition of the pyrolysis, and then, injected into the reactor of the pyrolysis process. The data were collected in surveys administered by a supervisor from company J, located at Incheon, Korea. The company used 7,936 tonnes of wood waste to produce 7,508 tonnes of wood chips. Around 107,120 $\mathrm{kWh}$ of electricity and 53,650 liters $(44,529 \mathrm{~kg})$ of diesel were used for the process. Data were reconstructed for analyzing the environmental impact of one tonne of wood waste. Around 13.50 $\mathrm{kWh}$ of electricity and 6.76 liters $(5.61 \mathrm{~kg})$ of diesel were used for pretreatment of one tonne of wood waste, and 0.946 tonnes of wood chip were produced.

\subsubsection{Carbonization process}

Wood charcoal was produced from wood chip by a low temperature pyrolysis process. Pretreated wood waste chip was injected to a carbonization furnace. Data was collected by survey interviews targeting a senior engineer, Dr. Park working in National Institute of Forest Science, Seoul. A rotary kiln type furnace as shown in Fig. 3 was developed for the carbonization process by Seyoung Co. Ltd. Approximately 100 liters (83 kg) of light fuel were consumed for initial ignition and internal heating of the kiln for 2.5 hours. The generated gas and smoke for the carbonization process was collected and used for heating by recirculation. Therefore, additional energy was not required after the initial operation of the kiln. In addition, hazardous gases or wastes were not discharged from the carbonization process. Approximately $500 \mathrm{~kg}$ of wood waste chip based on dry weight was feeding for one hour. Carbonization 


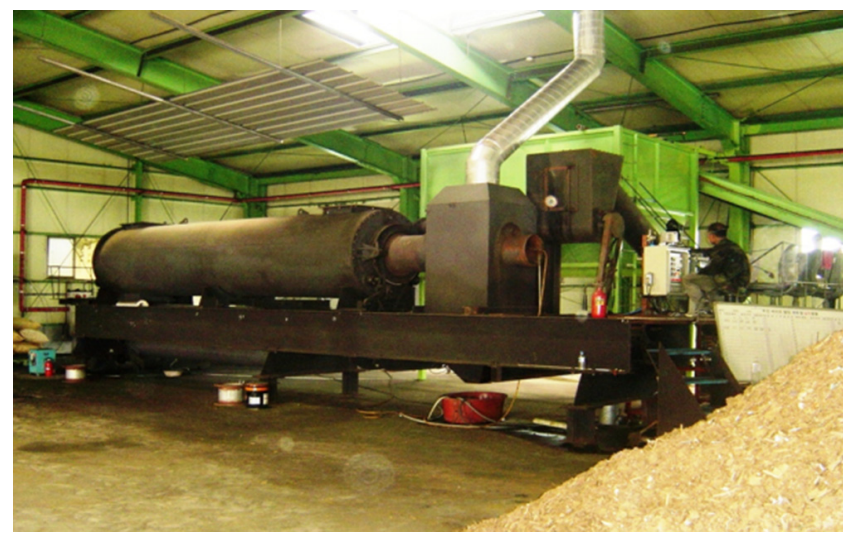

Fig. 3. Rotary kiln for the carbonization (Courtesy of Seyoung Co. Ltd.).

yield was $25 \%$ based on dry weight. Therefore, around $125 \mathrm{~kg}$ of charcoal was produced from $500 \mathrm{~kg}$ of dried chip. The residence time was $30 \mathrm{~min}$ at $600^{\circ} \mathrm{C}$ or $60 \mathrm{~min}$ at $800^{\circ} \mathrm{C}$ for the carbonization. The carbonization step was performed in optimal conditions for increasing the highest production yield. Waste heat was recovered and used for the rotary kiln reactor for carbonization in the system boundary.

Pyroligneous acid was produced by condensing the generated gas from the process. Wood charcoal and wood vinegar were produced from around $30 \%$ and $25 \%$ of wood feedstock, respectively, based on weight. Wood charcoal was used as a raw material for AC production, and wood vinegar was used as a raw material for organic agriculture, wastewater treatment, odor filtering, medicine, and chemicals.

\subsubsection{Activation process}

The data for activation was collected from a company, Woosung Tech, located in Gyeonggi province. Carbonized charcoal was injected to a rotary kiln reactor for steam activation. It had a diameter of $1.25 \mathrm{~m}$ with $11 \mathrm{~m}$ length. The slope was about $2 \%$ and the rotation rate was 3-5 rpm. The motors of the rotary kiln and the feeding equipment were $5 \mathrm{hp}$ and $0.5 \mathrm{hp}$, respectively. The burner has $0.25 \mathrm{hp}$. The energy consumption of the burner was 20 liters of kerosene oil per hour. The condition for activation process was at $900-1,000^{\circ} \mathrm{C}$ for $3-4 \mathrm{~h}$ of residence time. The rotary kiln has a capacity of 8 tonnes carbonized charcoal per day, and the yield was $50 \%$ based on carbonized charcoal. Therefore, 4 tonnes of AC were produced per day. Steam was supplied to the reactor by a steam generator $(0.2 \mathrm{hp})$ at reaching temperature of $500^{\circ} \mathrm{C}$. Approximately, $300 \mathrm{~kg}$ of water per hour was used. The activation process involves developing a microporous structure form the carbonized charcoal by carbon oxidation. $0.25 \mathrm{hp}$ of scrubber was used in the process. BET surface area was around 1,500-2,000 $\mathrm{m}^{2} / \mathrm{g}$, and adsorption capability for iodine was around 1,000 mg/g [44].

\subsubsection{Post treatment process}

Following oxidization, produced AC was cooled and sorted. The AC is processed for different applications include GAC, powder AC, and impregnated carbon. The raw data for biomass and energy consumption for each production step was summarized in Table 1.

\subsection{Functional Unit and Assumptions}

The functional unit was one tonne of wood waste discharged from a forestry or relevant industry. The reference flow for a quantitative analysis was one tonne of wood waste. According to the literature reviews, it was reported that around $90 \%$ of collected wood waste was generated in the forest. The tree types of wood waste were mostly pines and oaks containing the thinning small diameter timber and infected trees by Bursaphelenchus xylophilus or oak wilt. Around $10 \%$ of wood waste was the discarded plywood generated from construction areas [45].

Assumptions applied for the study include:

- The system boundary included a pretreatment stage, carbonization, and activation stage for producing AC.

- The transportation stage from the generation of wood waste to a treatment facility was excluded.

- Pyroligneous acid produced from carbonization process for AC production system was used as valuable products, raw material for medical substance, methanol acetone, acetic acid, and soluble tar. Use of pyrolingneous acid was not included in the system boundary since data on the use stage of byproducts were insufficient.

- A product made of by-products or recycled materials could replace the same amount of product made of virgin raw materials. Therefore, allocation was avoided [46].

\section{Results and Discussion}

\subsection{Environmental Impact Analysis}

The goal of this study was to evaluate the environmental impacts of AC production process following ISO 14044 guidelines using LCA methodology. LCA is a method for determining a broad set of collected and organized data [47] and using the environmental impacts of consumer products across the entire value chain [48].

Table 1. Input Data for Materials and Energy Consumption

\begin{tabular}{|c|c|c|c|c|c|c|}
\hline & & Material/Energy & Chipping & Drying & Carbonization & Activation \\
\hline \multirow[t]{5}{*}{ Input } & Materials & Wood waste (kg) & $1.00 \mathrm{E}+03$ & $1.00 \mathrm{E}+03$ & $9.46 \mathrm{E}+02$ & $2.37 \mathrm{E}+02$ \\
\hline & & Water (kg) & & & & $7.11 \mathrm{E}+01$ \\
\hline & Energy & Diesel (kg) & $5.61 \mathrm{E}+00$ & & $1.97 \mathrm{E}+01$ & \\
\hline & & Electricity (kWh) & & $1.35 \mathrm{E}+01$ & & $1.10 \mathrm{E}+00$ \\
\hline & & Carosene (kg) & & & & $5.54 \mathrm{E}+00$ \\
\hline Output & Materials & Wood product (kg) & $1.00 \mathrm{E}+03$ & $9.46 \mathrm{E}+02$ & $2.37 \mathrm{E}+02$ & $1.18 \mathrm{E}+02$ \\
\hline
\end{tabular}


As LCA enables comparison between the environmental effect of each scenario studied while considering several impact categories, it can be properly concluded that LCA is a valuable tool to select an environmentally sound alternative [49]. The input material was one tonne of wood wastes for the system. For the AC production process analyzed in this study, approximately 25.3 $\mathrm{kg}$ of diesel, $5.54 \mathrm{~kg}$ of carosene, $14.6 \mathrm{kWh}$ of electricity, and $71.1 \mathrm{~kg}$ of water were used. About $118 \mathrm{~kg}$ of AC was produced from one tonne of raw wood waste. The produced AC from the company, Woosung Tech, has supported to a drinking water plant for water purifying in Echeon city, Gyeonggi province. Table 2 summarized the inventory analysis results related to natural energy resources and primary GHGs emissions for each step. As we discussed about the process description in Fig. 2, LCI was established for the eighty seven input materials and one hundred and eighty two output emissions from the system.

The result of the environmental impact of the AC production system is shown in Table 3. The AC system produced environmental impacts of $8.43 \mathrm{E}-01 / \mathrm{y}$. for Abiotic Depletion Potential (ADP), 4.81E-02 kg of $\mathrm{SO}_{2}$-eq. for Acidification Potential (AP), 4.21E-03 $\mathrm{kg}$ of $\mathrm{PO}_{4}^{-3}$-eq. for Eutrophication Potential (EP), 2.00E-02 kg of
1,4 DCB-eq. for Freshwater Aquatic Ecotoxicity Potential (FAETP), $1.04 \mathrm{E}+01 \mathrm{~kg}$ of $\mathrm{CO}_{2}$-eq. for GWP, $1.42 \mathrm{E}-01 \mathrm{~kg}$ of $1,4 \mathrm{DCB}$-eq. for Human Toxicity Potential (HTP), 9.56E $+00 \mathrm{~kg}$ of 1,4DCB-eq. of Marine Aquatic Ecotoxicity Potential (MAETP), 9.67E-08 kg of CFC 11-eq. for Ozone Depletion Potential (ODP), 2.09E-02 kg of $\mathrm{C}_{2} \mathrm{H}_{4}$-eq. for Photochemical Oxidant Creation Potential (POCP), and 3.08E-06 kg of 1,4 DCB-eq. for Terrestrial Ecotoxicity Potential (TETP) from one tonne of wood waste. As shown in Fig. 4, the carbonization process mostly contributed to the ADP, however, pretreatment process of drying impacted the EP and GWP. Activation process dominantly impacted on HTP, ODP, and TETP. We analyzed GWP gases generated for the AC production process. The result shows the drying process produced the highest GWP gases of $6.68 \mathrm{E}+00 \mathrm{~kg}$ of $\mathrm{CO}_{2}$-eq., and the chipping process produced the lowest GWP gases of 3.83E-01 kg of $\mathrm{CO}_{2}$-eq. (Table 4).

The results of analyzing environmental impacts were recalculated for comparison with those reported by studies in the literature review. Table 5 shows the impact category indicators based on $1 \mathrm{~kg}$ of AC production from wood waste found in this study and other researches. The environmental burdens of this study are lower than coal or olive waste cake [8, 27, 41]. GWPs of AC

Table 2. Inventory Analysis of the AC Production System (Unit: kg)

\begin{tabular}{llccccc}
\hline & & Chipping & Drying & Carbonization & Activation & Total \\
\hline \multirow{3}{*}{ Input } & Water & $8.63 \mathrm{E}-01$ & $2.80 \mathrm{E}-01$ & $3.03 \mathrm{E}+00$ & $7.49 \mathrm{E}+01$ & $7.91 \mathrm{E}+01$ \\
& Coal & $1.65 \mathrm{E}-02$ & $2.37 \mathrm{E}+00$ & $5.81 \mathrm{E}-02$ & $2.10 \mathrm{E}-01$ & $2.66 \mathrm{E}+00$ \\
& Crude oil & $5.74 \mathrm{E}+00$ & $2.94 \mathrm{E}-01$ & $2.01 \mathrm{E}+01$ & $5.74 \mathrm{E}+00$ & $3.19 \mathrm{E}+01$ \\
& Natural gas & $3.15 \mathrm{E}-01$ & $3.04 \mathrm{E}-01$ & $1.11 \mathrm{E}+00$ & $3.15 \mathrm{E}-02$ & $1.76 \mathrm{E}+00$ \\
\hline & Carbon dioxide & $3.82 \mathrm{E}-01$ & $6.58 \mathrm{E}+00$ & $1.34 \mathrm{E}+00$ & $1.85 \mathrm{E}+00$ & $1.02 \mathrm{E}+01$ \\
& CFCs & $1.95 \mathrm{E}-13$ & $0.00 \mathrm{E}+00$ & $6.84 \mathrm{E}-13$ & $1.20 \mathrm{E}-11$ & $1.29 \mathrm{E}-11$ \\
& HCFC-22 & $1.93 \mathrm{E}-14$ & $0.00 \mathrm{E}+00$ & $6.77 \mathrm{E}-14$ & $1.19 \mathrm{E}-12$ & $1.28 \mathrm{E}-12$ \\
& Methane & $3.54 \mathrm{E}-05$ & $4.77 \mathrm{E}-03$ & $1.24 \mathrm{E}-04$ & $7.02 \mathrm{E}-04$ & $5.63 \mathrm{E}-03$ \\
& NOx & $3.39 \mathrm{E}-04$ & $1.61 \mathrm{E}-02$ & $1.19 \mathrm{E}-03$ & $1.40 \mathrm{E}-02$ & $3.16 \mathrm{E}-02$ \\
& SO & $7.10 \mathrm{E}-04$ & $2.20 \mathrm{E}-02$ & $2.49 \mathrm{E}-03$ & $2.52 \mathrm{E}-02$ & $5.04 \mathrm{E}-02$ \\
& Wastewater & $4.98 \mathrm{E}-01$ & $0.00 \mathrm{E}+00$ & $1.75 \mathrm{E}+00$ & $2.13 \mathrm{E}+00$ & $4.38 \mathrm{E}+00$ \\
& Waste & $1.37 \mathrm{E}-03$ & $7.99 \mathrm{E}-01$ & $4.82 \mathrm{E}-03$ & $1.11 \mathrm{E}-01$ & $9.16 \mathrm{E}-01$ \\
\hline
\end{tabular}

Table 3. Result of the Characterization of the AC Production System from One Tonne of Wood Waste

\begin{tabular}{|c|c|c|c|c|c|c|}
\hline & Unit & Chipping & Drying & Carbonization & Activation & Total \\
\hline $\mathrm{ADP}$ & 1/year [37, 50] & $1.48 \mathrm{E}-01$ & 2.33E-02 & 5.19E-01 & $1.44 \mathrm{E}-01$ & 8.34E-01 \\
\hline $\mathrm{AP}$ & $\mathrm{kg} \mathrm{SO}{ }_{2}$-eq. & 7.84E-04 & $1.13 \mathrm{E}-02$ & $2.75 \mathrm{E}-03$ & 3.33E-02 & $4.81 \mathrm{E}-02$ \\
\hline $\mathrm{EP}$ & $\mathrm{kg} \mathrm{PO}_{4}{ }^{3-}$-eq. & $5.36 \mathrm{E}-05$ & $2.10 \mathrm{E}-03$ & $1.88 \mathrm{E}-04$ & $1.86 \mathrm{E}-03$ & $4.21 \mathrm{E}-03$ \\
\hline FAETP & kg 1,4 DCB-eq. & $1.45 \mathrm{E}-03$ & $4.76 \mathrm{E}-04$ & $5.08 \mathrm{E}-03$ & $1.30 \mathrm{E}-02$ & $2.00 \mathrm{E}-02$ \\
\hline GWP & kg $\mathrm{CO}_{2}$-eq. & 3.83E-01 & $6.68 \mathrm{E}+00$ & $1.34 \mathrm{E}+00$ & $1.95 \mathrm{E}+00$ & $1.04 \mathrm{E}+01$ \\
\hline HTP & kg 1,4 DCB-eq. & $1.21 \mathrm{E}-03$ & $1.49 \mathrm{E}-03$ & $4.25 \mathrm{E}-03$ & $1.35 \mathrm{E}-01$ & $1.42 \mathrm{E}-01$ \\
\hline MAETP & kg 1,4 DCB-eq. & 1.07E-01 & $3.41 \mathrm{E}+00$ & $3.75 \mathrm{E}-01$ & $5.67 \mathrm{E}+00$ & $9.56 \mathrm{E}+00$ \\
\hline ODP & kg CFC11-eq. & $5.88 \mathrm{E}-10$ & $1.54 \mathrm{E}-10$ & 2.06E-09 & 9.39E-08 & 9.67E-08 \\
\hline POCP & $\mathrm{kg} \mathrm{C}_{2} \mathrm{H}_{4}$-eq. & $6.25 \mathrm{E}-05$ & 4.63E-03 & 2.19E-04 & 1.60E-02 & 2.09E-02 \\
\hline TETP & kg 1,4 DCB-eq. & $1.86 \mathrm{E}-08$ & $2.70 \mathrm{E}-10$ & $6.54 \mathrm{E}-08$ & 2.99E-06 & 3.08E-06 \\
\hline
\end{tabular}


Table 4. Result of the GWP for the AC Production System from One Tonne of Wood Waste (unit: $\mathrm{kg} \mathrm{CO}_{2}$ equivalent)

\begin{tabular}{lccccc}
\hline & Chipping & Drying & Carbonization & Activation & Total \\
$\mathrm{CO}_{2}$ & $3.82 \mathrm{E}-01$ & $6.58 \mathrm{E}+00$ & $1.34 \mathrm{E}+00$ & $1.85 \mathrm{E}+00$ & $2.02 \mathrm{E}+01$ \\
$\mathrm{CFC}-11$ & $3.28 \mathrm{E}-10$ & & $1.15 \mathrm{E}-09$ & $2.02 \mathrm{E}-08$ & $5.17 \mathrm{E}-08$ \\
$\mathrm{CFC}-114$ & $7.81 \mathrm{E}-10$ & & $2.74 \mathrm{E}-09$ & $4.82 \mathrm{E}-08$ & $9.93 \mathrm{E}-09$ \\
$\mathrm{CFC}-12$ & $1.50 \mathrm{E}-10$ & & $5.27 \mathrm{E}-10$ & $9.25 \mathrm{E}-09$ & $8.58 \mathrm{E}-09$ \\
$\mathrm{CFC}-13$ & $1.30 \mathrm{E}-10$ & & $4.55 \mathrm{E}-10$ & $7.99 \mathrm{E}-09$ & $5.42 \mathrm{E}-05$ \\
$\mathrm{Halon}-1301$ & $3.29 \mathrm{E}-07$ & $8.62 \mathrm{E}-08$ & $1.16 \mathrm{E}-06$ & $5.26 \mathrm{E}-05$ & $2.17 \mathrm{E}-09$ \\
$\mathrm{HCFC}-22$ & $3.28 \mathrm{E}-11$ & & $1.15 \mathrm{E}-10$ & $2.02 \mathrm{E}-09$ & $1.18 \mathrm{E}-01$ \\
$\mathrm{CH}$ & $7.43 \mathrm{E}-04$ & $1.00 \mathrm{E}-01$ & $2.61 \mathrm{E}-03$ & $1.47 \mathrm{E}-02$ & $9.19 \mathrm{E}-02$ \\
$\mathrm{~N}_{2} \mathrm{O}$ & $4.79 \mathrm{E}-05$ & $6.40 \mathrm{E}-03$ & $1.68 \mathrm{E}-04$ & $8.52 \mathrm{E}-02$ & $1.95 \mathrm{E}+00$ \\
$\mathrm{Total}$ & $3.83 \mathrm{E}-01$ & $6.68 \mathrm{E}+00$ & $1.34 \mathrm{E}+00$ & & $1.04 \mathrm{E}+01$ \\
\hline
\end{tabular}

Table 5. Characterized Environmental Impacts for $1 \mathrm{~kg}$ of AC Production Comparing with Other Technologies

\begin{tabular}{|c|c|c|c|c|c|c|}
\hline & \multirow{2}{*}{ Unit } & \multicolumn{2}{|c|}{ This study } & \multicolumn{3}{|c|}{ Literature data } \\
\hline & & Wood waste & Coconut shells & Olive waste cake [8] & Coal [41] & Coal [27] \\
\hline $\mathrm{ADP}$ & 1/year & 8.34E-04 & $2.34 \mathrm{E}-04$ & - & - & - \\
\hline $\mathrm{AP}$ & $\mathrm{kg} \mathrm{SO}$-eq. & 4.81E-05 & $1.96 \mathrm{E}-02$ & $1.08 \mathrm{E}-01$ & 5.33E-02 & $5.80 \mathrm{E}-03$ \\
\hline $\mathrm{EP}$ & $\mathrm{kg} \mathrm{PO}_{4}{ }^{3-}$-eq. & $4.21 \mathrm{E}-06$ & 1.17E-03 & 3.30E-02 & $2.50 \mathrm{E}-03$ & $5.20 \mathrm{E}-04$ \\
\hline FAETP & kg 1,4 DCB-eq. & 2.00E-05 & $4.64 \mathrm{E}-02$ & $4.90 \mathrm{E}+00$ & $3.43 \mathrm{E}-01$ & - \\
\hline GWP & kg $\mathrm{CO}_{2}$-eq. & $1.04 \mathrm{E}-02$ & $1.15 \mathrm{E}+00$ & $1.11 \mathrm{E}+01$ & $8.40 \mathrm{E}+00$ & $1.10 \mathrm{E}+01$ \\
\hline HTP & kg 1,4 DCB-eq. & $1.42 \mathrm{E}-04$ & $4.81 \mathrm{E}-01$ & $5.26 \mathrm{E}+00$ & $2.08 \mathrm{E}+00$ & - \\
\hline MAETP & kg 1,4 DCB-eq. & $9.56 \mathrm{E}-03$ & $3.42 \mathrm{E}+01$ & - & - & - \\
\hline ODP & kg CFC11-eq. & $9.67 \mathrm{E}-11$ & 3.35E-07 & $5.46 \mathrm{E}-07$ & $1.90 \mathrm{E}-07$ & - \\
\hline POCP & kg $\mathrm{C}_{2} \mathrm{H}_{4}$-eq. & 2.09E-05 & $1.87 \mathrm{E}-03$ & 7.00E-03 & $2.40 \mathrm{E}-03$ & $1.20 \mathrm{E}-03$ \\
\hline TETP & kg 1,4 DCB-eq. & 3.08E-09 & $1.06 \mathrm{E}-05$ & $1.60 \mathrm{E}-02$ & 1.69E-02 & - \\
\hline
\end{tabular}

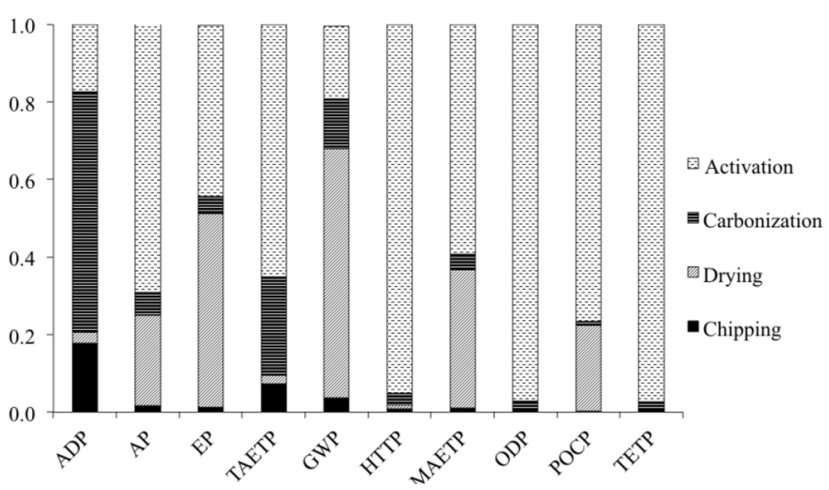

Fig. 4. Environmental impact assessment by relative characterization results for each step of chipping, drying, carbonization, activation.

production processes were approximately $11 \mathrm{~kg} \mathrm{CO}$-eq. for $1 \mathrm{~kg}$ AC production from coal [27]. The AC from the raw material of the coal process showed that electricity was the main factor responsible for the impact for the drying process and the pyrolysis process. The AC from olive waste cake showed that the impregnation sub-process of the chemical activation contributed to the environmental impacts. It was estimated that the concentrated
$\mathrm{H}_{3} \mathrm{PO}_{4}$ as an impregnating agent and energy inputs were the critical points causing higher environmental impacts [8].

\subsection{Avoided Impact Analysis}

An avoided impact was conducted to calculate the efficiencies of GHGs reduction on the systems. Byproducts generated from the product manufacturing process can be used as raw materials for other production systems, resulting in a reduction of the use of virgin raw materials in other product systems. It has been generally accepted that the use of recycled materials is environmentally preferable to that of virgin raw materials [42]. In this study, GWP discharged from $1 \mathrm{~kg}$ of AC production systems from wood wastes and coconut shells were $1.04 \mathrm{E}-02 \mathrm{~kg} \mathrm{CO}_{2}$-eq. and $1.15 \mathrm{E}+00 \mathrm{~kg}$ $\mathrm{CO}_{2}$-eq., respectively (Table 6). We evaluated the environmental credit of AC production from $1 \mathrm{~kg}$ of wood waste. The results showed that the AC production of wood waste reduced GWP, $1.14 \mathrm{E}+00 \mathrm{~kg} \mathrm{CO}$-eq. more than coconut shells, $1.11 \mathrm{E}+01 \mathrm{~kg}$ $\mathrm{CO}_{2}$-eq. more than olive waste, and average $9.69 \mathrm{E}+00 \mathrm{~kg} \mathrm{CO}$-eq. more than coal.

Environmental credits of AC production from wood waste recycling compared with other raw materials are presented in Fig. 5. This study showed that the wood waste recycling has advantages 


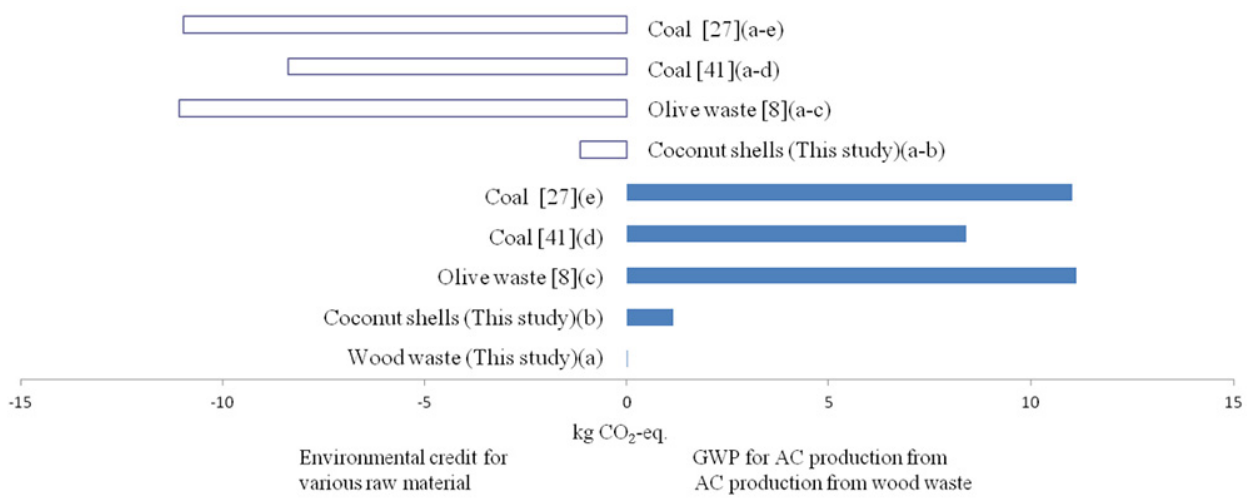

Fig. 5. Avoid impact analysis of AC production using wood waste. GWP for AC production from wood waste was compared with the literature data and environmental credits were calculated.

Table 6. GWP of $1 \mathrm{~kg}$ of AC Production System from Wood Waste

\begin{tabular}{|c|c|c|c|c|c|c|c|c|}
\hline \multicolumn{5}{|c|}{ GWP production for AC } & \multirow{2}{*}{\multicolumn{4}{|c|}{ Environmental credit }} \\
\hline \multicolumn{2}{|c|}{ This study } & \multicolumn{3}{|c|}{ Literature data } & & & & \\
\hline $\begin{array}{l}\text { Wood waste } \\
\text { (a) }\end{array}$ & $\begin{array}{l}\text { Coconut shells } \\
\text { (b) }\end{array}$ & $\begin{array}{c}\text { Olive waste [8] } \\
\text { (c) }\end{array}$ & $\begin{array}{l}\text { Coal [41] } \\
\text { (d) }\end{array}$ & $\begin{array}{c}\text { Coal [27] } \\
(\mathbf{e})\end{array}$ & $\begin{array}{c}\text { Coconut shells } \\
\text { (a-b) }\end{array}$ & $\begin{array}{c}\text { Olive waste [8] } \\
\text { (a-c) }\end{array}$ & $\begin{array}{l}\text { Coal [41] } \\
\quad(a-d)\end{array}$ & $\begin{array}{c}\text { Coal [27] } \\
\quad \text { (a-e) }\end{array}$ \\
\hline $1.04 \mathrm{E}-02$ & $1.15 \mathrm{E}+00$ & $1.11 \mathrm{E}+01$ & $8.40 \mathrm{E}+00$ & $1.10 \mathrm{E}+01$ & $-1.14 \mathrm{E}+00$ & $-1.11 \mathrm{E}+01$ & $-8.39 \mathrm{E}+00$ & $-1.10 \mathrm{E}+01$ \\
\hline
\end{tabular}

Table 7. Comparison with One Tonne of Wood Waste Recycling or Disposal Options

\begin{tabular}{|c|c|c|c|c|c|c|}
\hline & \multirow[b]{2}{*}{ Unit } & \multicolumn{3}{|c|}{ Environmental impact } & \multicolumn{2}{|c|}{ Environmental credit } \\
\hline & & $\begin{array}{l}\text { AC production (This study) } \\
\text { (a) }\end{array}$ & $\begin{array}{l}\text { Land filling [51] } \\
\text { (f) }\end{array}$ & $\begin{array}{l}\text { Wood pellet [51] } \\
\text { (g) }\end{array}$ & (a)-(f) & (a)-(g) \\
\hline $\mathrm{ADP}$ & 1/year & 8.34E-01 & $0.00 \mathrm{E}+00$ & 4.25E-02 & 8.34E-01 & 7.92E-01 \\
\hline $\mathrm{AP}$ & kg SO${ }_{2}$-eq. & 4.81E-02 & $2.18 \mathrm{E}-01$ & $1.34 \mathrm{E}-01$ & $-1.70 \mathrm{E}-01$ & $-8.59 \mathrm{E}-02$ \\
\hline $\mathrm{EP}$ & $\mathrm{kg} \mathrm{PO}_{4}{ }^{3-}$-eq. & 4.21E-03 & $2.22 \mathrm{E}-02$ & 1.99E-02 & $-1.80 \mathrm{E}-02$ & $-1.57 \mathrm{E}-02$ \\
\hline FAETP & kg 1,4 DCB-eq. & 2.00E-02 & $0.00 \mathrm{E}+00$ & $1.33 \mathrm{E}+00$ & 2.00E-02 & $-1.31 \mathrm{E}+00$ \\
\hline GWP & kg CO -eq. & $1.04 \mathrm{E}+01$ & $1.73 \mathrm{E}+02$ & $1.52 \mathrm{E}+01$ & $-1.63 \mathrm{E}+02$ & $-4.80 \mathrm{E}+00$ \\
\hline HTP & kg 1,4 DCB-eq. & $1.42 \mathrm{E}-01$ & 1.96E-01 & $1.82 \mathrm{E}+01$ & $-5.40 \mathrm{E}-02$ & $-1.81 \mathrm{E}+01$ \\
\hline MAETP & kg 1,4 DCB-eq. & $9.56 \mathrm{E}+00$ & $0.00 \mathrm{E}+00$ & $9.93 \mathrm{E}+03$ & $9.56 \mathrm{E}+00$ & $-9.92 \mathrm{E}+03$ \\
\hline ODP & kg CFC11-eq. & 9.67E-08 & $0.00 \mathrm{E}+00$ & 7.81E-07 & $9.67 \mathrm{E}-08$ & $-6.84 \mathrm{E}-07$ \\
\hline POCP & $\mathrm{kg} \mathrm{C}_{2} \mathrm{H}_{4}$-eq. & 2.09E-02 & 7.81E-02 & 1.30E-02 & $-5.72 \mathrm{E}-02$ & 7.90E-03 \\
\hline TETP & kg 1,4 DCB-eq. & 3.08E-06 & $0.00 \mathrm{E}+00$ & 9.23E-02 & $3.08 \mathrm{E}-06$ & $-9.23 \mathrm{E}-02$ \\
\hline
\end{tabular}

for natural resources prevention such as coals. From the waste management disposal point, the cost savings and pollutants reduction for wood waste disposal including incineration or landfilling are additional benefits.

\subsection{Comparison with Wood Waste Disposal Options}

This study compared and analyzed the wood waste recycling of AC production system and other methods such as wood pellet production system and disposal system of landfilling by using Ecoinvent data [51]. The AC production of wood waste has an environmental credit to AP, EP, GWP, HTP, POCP in comparison to landfilling disposal. The environmental credit for GWP of AC production from one tonne of wood waste was $-163 \mathrm{~kg} \mathrm{CO}_{2}$-eq., more beneficial than the same amount of wood waste disposal AC production of wood waste has an environmental credit to AP, EP, GWP, HTP, MAETP, ODP, and TETP in comparison with the wood pellet production. The environmental credit for GWP of $\mathrm{AC}$ production from one tonne of wood waste was $-4.8 \mathrm{~kg} \mathrm{CO}_{2}$-eq., more beneficial than the same amount of wood pellet production (Table 7).

\subsection{Costs for AC Production}

Material recycling from waste stream can reduce the consumption of natural resources and decrease the disposal cost such as landfill and incineration. The AC production from wood wastes positively and sustainably impacts on the protection for natural environment. 
In the economic viewpoint, recycling process can reduce waste disposal costs and environmental restoration costs. Therefore, recycling systems system need to be promoted even though the production costs from wastes are higher than the costs from virgin raw materials. We surveyed the AC production costs in the selected companies for this study. From the visiting survey interviews with the senior engineering project manager in the company, Seyoung Co. Ltd., we found the costs for one tonne of AC production were approximately $\$ 700.40$. The yield for carbonization process and activation process were $20 \%$ and $50 \%$, respectively. From the internal data of the company, two tonnes of charcoal were produced from ten tonnes of wood chip through carbonization process. Therefore, one tonne of AC was produced from ten tonnes of wood chip. From the survey, we found that approximately $\$ 560.30$ was required for two tonnes of charcoal production $(\$ 466.90$ for material cost of wood chip, $\$ 46.70$ for fuel, and $\$ 46.70$ for labor cost). For the activation process, approximately $\$ 140.10$ was required for one tonne of AC production ( $\$ 93.40$ for fuel and $\$ 46.70$ for labor cost).

\section{Conclusions}

This study evaluated the environmental impacts of the AC production systems using an expanded system boundary. The feedstock was wood waste generated by the production activities in industry or forest. Wood is a renewable resource that can be used for wood products, such as particleboard or medium density fiberboard and energy production, such as wood pellet used for combined heat and power. In Korea, an energetic policy of renewable portfolio standard has been suggested to increase production of energy from renewable energy sources including wood. On the other side, imports for AC have been steeply increased by consumer's demand for indoor air or water purification. GHGs are generally produced not only all products manufacturing process but also their transportation. According to the 'polluter pays principle' with socially and politically suggested for solving the issue, the obligation would be a controversial issue between import and export countries. In addition, the natural disaster, such as flooding, drought, extreme heat and cold temperature, and hurricanes, has been increasing throughout the world, and it is widely understood that climate change provides the fundamental cause with direct and indirect impacts. Therefore, a worldwide cooperative effort to mitigate the global warming based on climate change impacts is required by material recycling and resource conservation.

This study was performed to analyze an environmental impact for AC production process using wood wastes and also review the process as one of alternatives of import substitution and waste disposal. The recycling of wood waste is influenced by the market. Due to the small scale of wood waste generated by forestry and agriculture focused in this study, the transportation stage from the wood waste generation area to facilities for recycling or storage is economically not feasible compared to industrial wood waste or construction wood waste generated on a large scale. These wood wastes are remained in environment, used as landfill or treated by open burning. These activities negatively impact on the natural environment and public health. Therefore, the support system for AC production from wood wastes can contribute to environmentally sustainable development as well as economically reducing waste disposal costs.

This study evaluated recycling systems by using the wood waste from feedstock generated on a small scale in terms of waste management and byproduct use. In this study, we evaluated that GWP discharged from $1 \mathrm{~kg}$ of AC production systems from wood wastes and coconut shells were $1.04 \mathrm{E}-02 \mathrm{~kg} \mathrm{CO}_{2}$-eq. and $1.15 \mathrm{E}+00 \mathrm{~kg}$ $\mathrm{CO}_{2}$-eq., respectively. The results of an avoided impact analysis showed that the systems contribute to carbon reduction. The AC production system has an environmental burden that is lower than the environmental benefit in optimized conditions. This study also demonstrated the environmental credit of AC production from $1 \mathrm{~kg}$ of wood waste. The study results showed that the AC production of wood waste reduced GWP, $1.14 \mathrm{E}+00 \mathrm{~kg} \mathrm{CO}_{2}$-eq. more than coconut shells, $1.11 \mathrm{E}+01 \mathrm{~kg} \mathrm{CO}$-eq. more than olive waste, and average $9.69 \mathrm{E}+00 \mathrm{~kg} \mathrm{CO}$-eq. more than coal. We analyzed the wood wastes recycling of AC production process and other recycling or disposal technologies. Ecoinvent data was used for wood pellet production process and wood waste landfilling process. The environmental credit for GWP of AC production from one tonne of wood waste was $163 \mathrm{~kg} \mathrm{CO}_{2}$-eq. and $4.8 \mathrm{~kg} \mathrm{CO}_{2}$-eq. more beneficial than the same amount of wood waste disposal by landfilling and wood pellet production, respectively. From the visiting survey interviews with the senior engineer, we found the costs for one tonne of AC production were approximately $\$ 700.40$. The costs may be higher than the production costs using virgin raw materials. However, AC production from wastes can be expected to offset the disposal costs. The results of this study suggest that AC production process from wood wastes can be an alternative method environmentally and economically. This study has a limitation in terms of quantifying the environmental impacts due to data deficiency, and future research is required to improve the reliability of the data. The data from the selected facilities may not represent national or global trends. In spite of this limitation, this study is expected to support related researches.

\section{Acknowledgments}

The authors would like to give their special thanks to Seyoung Co. Ltd., and Woosung Tech for their helpful advice.

\section{Nomenclature}

Pa By-product (wood waste)

$\mathrm{Pb}$ Raw material (coal/coconut shell)

\section{References}

1. Hwang I, Kobayashi J, Kawamoto K. Characterization of products obtained from pyrolysis and steam gasification of wood waste, RDF, and RPF. Waste Manage. 2014;34:402-410. 
2. Bansal RC, Goyal M. Activated carbon adsorption. CRC Press: Taylor \& Francis; 2005. p. 46-51.

3. Kadirvelu K, Thamaraiselvi K, Namasivayam C. Removal of heavy metals from industrial wastewaters by adsorption onto activated carbon prepared from an agricultural solid waste. Bioresour. Technol. 2001;76:63-65.

4. Olufemi BA, Otolorin F. Comparative adsorption of crude oil using mango (Mangnifera indica) shell and mango shell activated carbon. Environ. Eng. Res. 2017;22:384-392.

5. Yahya MA, Al-Qodah Z, Ngah CWZ. Agricultural bio-waste materials as potential sustainable precursors used for activated carbon production: A review. Renew. Sust. Energ. Rev. 2015a;46: 218-235.

6. Malik R, Ramteke DS, Wate SR. Physico-chemical and surface characterization of adsorbent prepared from groundnut shell by $\mathrm{ZnCl}_{2}$ activation and its ability to adsorb colour. Indian J. Chem. Technol. 2006;13:319-328.

7. McDougall GJ. The physical nature and manufacture of activated carbon. J. South. Afr. Inst. Min. Metall. 1991;91:109-120.

8. Hjaila K, Baccar R, Sarrà $M$, Gasol CM, Blànquez $P$. Environmental impact associated with activated carbon preparation from olive-waste cake via life cycle assessment. J. Environ. Manage. 2013;130:242-247.

9. Chen R, Li L, Liu Z, et al. Preparation and characterization of activated carbon from tobacco stem by chemical activation. J. Air Waste Manage. Assoc. 2017;67:713-724.

10. Yahya MA, Al-Qodah Z, Ngah CWZ, Hashim MA. Preparation and characterization of activated carbon from desiccated coconut residue by potassium hydroxide. Asian J. Chem. 2015b;27:2331-2336.

11. Ioannidou O, Zabaniotou A. Agricultural residues as precursors for activated carbon production - A review. Renew. Sust. Energ. Rev. 2007;11:1966-2005.

12. Chung CK. Utilization of discarded tree debris for commercial production of activated carbon. Sejongsi: Ministry of Agriculture. Food and Rural Affairs; 2000. p. 174-185 (in Korean).

13. Kim J, Chung C, Min B. A study on development of activated carbons from waste timbers. J. Korean Inst. Resour. Recycl. 2008;17:68-78 (in Korean).

14. Seppälä J, Hämäläinen RP. On the meaning of the distance-to-target weighting method and normalisation in life cycle impact assessment. Int. J. Life Cycle Assess. 2001;6:211-218.

15. Finnveden G. Valuation methods within LCA - Where are the values? Int. J. Life Cycle Assess. 1997;2:163-169.

16. Powell JC, Pearce DW, Craighill AL. Approaches to valuation in LCA impact assessment. Int. J. Life Cycle Assess. 1997;2:11-15.

17. Park PJ, Tahara K, Jeong IT, Lee KM. Comparison of four methods for integrating environmental and economic aspects in the end-of-life stage of a washing machine. Resour. Conserv. Recycl. 2006;48:71-85.

18. Kim H, Kim K, Park H. Life cycle assessment of the environmental infrastructures in operation phase: Case of an industrial waste incineration plant. Environ. Eng. Res. 2017;22:266-276.

19. Piao W, Kim Y. Evaluation of monthly environmental loads from municipal wastewater treatment plants operation using life cycle assessment. Environ. Eng. Res. 2016;21:284-290.
20. Fei F, Wen Z, Huang S, Clercq DD. Mechanical biological treatment of municipal solid waste: Energy efficiency, environmental impact and economic feasibility analysis. J. Clean. Prod. 2018;178:731-739.

21. Merrild H, Damgaard A, Christensen TH. Life cycle assessment of waste paper management: The importance of technology data and system boundaries in assessing recycling and incineration. Resour. Conserv. Recycl. 2008;52:1391-1398.

22. M'hamdi AI, Gusca J, Blumberga D, Zerouale A, Kandri NI. Comparative analysis of processed wood waste reuse possibilities after chemical delignification treatment. Energy Procedia 2017;113:289-296.

23. Nuss P, Gardner KH, Jambeck JR. Comparative life cycle assessment (LCA) of construction and demolition (C\&D) derived biomass and U.S. Northeast forest residuals gasification for electricity production. Environ. Sci. Technol. 2013;47:3463-3471.

24. Ripa M, Fiorentino G, Vacca V, Ulgiati S. The relevance of site-specific data in life cycle assessment (LCA). The case of the municipal solid waste management in the metropolitan city of Naples (Italy). J. Clean. Prod. 2017;142:445-460.

25. Rocha MH, Capaz RS, Lora EES, et al. Life cycle assessment (LCA) for biofuels in Brazilian conditions: A meta-analysis. Renew. Sust. Energ. Rev. 2014;37:435-459.

26. Alhashimi HA, Aktas CB. Life cycle environmental and economic performance of biochar compared with activated carbon: A meta-analysis. Resour. Conserv. Recycl. 2017;118:13-26.

27. Bayer P, Heuer E, Karl U, Finkel M. Economical and ecological comparison of granular activated carbon (GAC) adsorber refill strategies. Water Res. 2005;39:1719-1728.

28. Kim MH, Song HB, Song Y, Jeong IT, Kim JW. Evaluation of food waste disposal options in terms of global warming and energy recovery: Korea. Int. J. Energ. Environ. Eng. 2013; 4:1-12.

39. Zeng L, Zhu H, Ma Y, Huang J, Li G. Greenhouse gases emissions from solid waste: An analysis of Expo 2010 Shanghai, China. J. Mater. Cycles Waste Manage. 2014;16:616-622.

30. IPCC. Revised 1996 IPCC guidelines for national greenhouse gas inventories. Intergovernmental Panel on Climate Change, Meteorological Office, Bracknell. 1997.

31. ISO. Environmental management - Life cycle assessment Principles and framework. ISO 14040:2006(E). International Organization for Standardization, Geneva. 2006.

32. ISO. Environmental management - Life cycle assessment Requirement and guidelines. ISO 14044:2006(E) International Organization for Standardization, Geneva. 2006.

33. ISO. International Organization for Standardization/TR: Environmental management - Life cycle assessment - Examples of application of ISO 14041 to goal and scope definition and inventory analysis. ISO/TR 14049:2000(E). Geneva. 2000.

34. Schmidt JH, Holm P, Merrild A, Christensen P. Life cycle assessment of the waste hierarchy - A Danish case study on waste paper. Waste Manage. 2007;27:1519-1530.

35. Lee KM. A weighting method for the Korean Eco-Indicator. Int. J. Life Cycle Assess. 1999;4:161-165.

36. Lindfors LG, Christiansen K, Hoffman L, et al. Nordic guidelines on life cycle assessment. Nordic Council of Ministers. Nord 1995:20, Copenhagen. 1995. 
37. Seo S, Asce M, Aramaki T, Hwang Y, Hanaki K. Environmental impact of solid waste treatment methods in Korea. J. Environ. Eng. 2004;130:1-9.

38. Lopes E, Dias A, Arroja L, Capela I. Pereira F. Application of life cycle assessment to the Portuguese pulp and paper industry. J. Clean. Prod. 2003;11:51-59.

39. Ekvall T, Finnveden G. Allocation in ISO 14041 - A critical review. J. Clean. Prod. 2001;9:197-208.

40. ISO. Environmental management - Life cycle assessment Goal and scope definition and inventory analysis. ISO 14041:1998(E) International Organization for Standardization, Geneva. 1998.

41. Gabarrell X, Font M, Vicent T, Caminal G, Sarrà M, Blánquez P. A comparative life cycle assessment of two treatment technologies for the Grey Lanaset $\mathrm{G}$ textile dye: Biodegradation by Trametes versicolor and granular activated carbon adsorption. Int. J. Life Cycle Assess. 2012;17:613-624.

42. Lee KM, Park PJ. Estimation of the environmental credit for the recycling of granulated blast furnace slag based on LCA Resour. Conserv. Recycl. 2005;44:139-151.

43. EPA. Guidance on data quality assessment for life cycle inventory data. EPA/600/R-16/096. Washington D.C.; 2016.
44. Lee DW, Lee JK, Rhee BS, Ryu SK. Increase of specific surface area of carbon fiber. Korean Chem. Eng. Res. 1989;27:777-783 (in Korean).

45. KFS. Korean forest service. Statistical yearbook of forestry. Daejeon; 2017. 47.

46. Rigamonti L, Grosso M, Giugliano M. Life cycle assessment of sub-units composing a MSW management system. J. Clean. Prod. 2010;18:1652-1662.

47. De Marco I, Iannone R. Production, packaging and preservation of semi-finished apricots: A comparative life cycle assessment study. J. Food Eng. 2017;206:106-117.

48. Ingwersen WI, Gausman M, Weisbrod A, et al. Detailed life cycle assessment of Bounty ${ }^{\circledR}$ paper towel operations in the United States. J. Clean. Prod. 2016;131:509-522.

49. Coelho LMG, Lange LC. Applying life cycle assessment to support environmentally sustainable waste management strategies in Brazil. Resour. Conserv. Recycl. 2018;128:438-450.

50. Guinée JB, Heijungs R. A proposal for the definition of resource equivalency factors for use in product life-cycle assessment. Environ. Toxicol. Chem. 1995;14:917-925.

51. Ecoinvent. The Swiss Centre for Life cycle inventories. Ecoinvent (v3.2), Zurich, Switzerland; 2015. 